\title{
Fe-based amorphous soft magnetic powders fabricated by water atomization
}

\author{
Yong Li, Yang Yang, Chunming Li, Yunhu Zhang, Changjiang Song ${ }^{\mathrm{a}}$ and Qijie Zhai \\ State Key Laboratory of Advanced Special Steels, Shanghai University; 149 Yanchang Rd, Shanghai, 200072, \\ China
}

\begin{abstract}
Fe-Si-B-Cr-Mn-Al powders were prepared by water atomization. We studied the phase, morphology and properties of the atomized powders. Experiment results present that the completely amorphous phase is achieved in powders having a diameter less than $150 \mu \mathrm{m}$. The morphology of most of powders is spherical or elliptical. The atomized powder possess good thermal stability and excellent soft magnetic properties. Their average saturation magnetization is as high as $151.2 \mathrm{emu} / \mathrm{g}$.
\end{abstract}

Keywords: metallic glass; soft magnetic; powder; water atomization.

\section{Introduction}

Magnetic materials are of fundamental importance for several applications in the electrical and electronic industries ${ }^{[1]}$. Fe-based metallic glass has desirable soft magnetic properties of high saturation magnetization, low coercivity, and high electrical resistivity [2]. The Fe-based amorphous alloy has been intensely investigated. In 1982, the first amorphous alloy with a composition of $\mathrm{Fe}_{75} \mathrm{Si}_{10} \mathrm{~B}_{15}$ was produced by Inoue, and its diameter is $0.27 \mathrm{~mm}$. Then in $1995 \mathrm{Fe}_{73} \mathrm{Al}_{5} \mathrm{Ga}_{2} \mathrm{P}_{11} \mathrm{C}_{5} \mathrm{~B}_{4}$ metallic glass with a diameter of $1 \mathrm{~mm}$ was prepared [4]. Many other Fe-based amorphous alloy were subsequently synthesized, such as, $\mathrm{Fe}_{65} \mathrm{Co}_{10} \mathrm{Ga}_{5} \mathrm{P}_{12} \mathrm{C}_{4} \mathrm{~B}_{4}$ [5], $\mathrm{Fe}_{62.8} \mathrm{Co}_{10} \mathrm{~B}_{13.5} \mathrm{Si}_{10} \mathrm{Nb}_{3} \mathrm{Cu}_{0.7}$ [6], $\mathrm{Fe}_{71.2} \mathrm{C}_{7.0} \mathrm{Si}_{3.3} \mathrm{~B}_{5.5} \mathrm{P}_{8.7} \mathrm{Cr}_{2.3} \mathrm{Al}_{2.0}[7]$ and $\mathrm{Fe}_{69} \mathrm{Cr}_{2} \mathrm{Mo}_{5} \mathrm{P}_{12} \mathrm{C}_{10} \mathrm{~B}_{2}[8]$.

In the development of $\mathrm{Fe}$-based alloys, the $\mathrm{Fe}-\mathrm{Si}-\mathrm{B}$ system is frequently researched, because of the fairly high saturation magnetization, no intrinsic magneto-crystalline anisotropy, low cost and the remarkable productivity [9]. But, its glass forming ability is very poor, and the thickness of ribbons made by melt-spinning is usually smaller than $25 \mu \mathrm{m}$. As a result, the amorphous alloy in large size is difficult to be prepared, which is one of the main bottleneck restricting the application of this amorphous alloy [10.11]. Powder metallurgy is a very good method to prepare bulk amorphous alloy, because the size and shape of alloy are easy to be controlled in the process of powder metallurgy [12, 13].

It is well known that the first procedure of powder metallurgy is to prepare high quality amorphous powders. In this work, we fabricated $\mathrm{Fe}-\mathrm{Si}-\mathrm{B}-\mathrm{Cr}-\mathrm{Mn}-\mathrm{Al}$ metallic glass powders by using wateratomization. The $\mathrm{Cr}, \mathrm{Al}, \mathrm{Mn}$ elements are added to improve the glass forming ability. The phase, morphology and properties of the atomized powders were examined.

a Corresponding author : riversxiao@163.com 


\section{Experimental}

The powders with a composition of $\mathrm{Fe}_{76} \mathrm{Si}_{13} \mathrm{~B}_{7} \mathrm{Cr}_{2} \mathrm{Mn}_{1} \mathrm{Al}_{1}$ were fabricated by water atomization. After screening, the powder particles were divided into the following groups according to the size: $0-53 \mu \mathrm{m}$, 53-63 $\mu \mathrm{m}, 63-75 \mu \mathrm{m}, 75-106 \mu \mathrm{m}$, and 106-150 $\mu \mathrm{m}$. The powders with diameter above $150 \mu \mathrm{m}$ were discarded. Examination of phase and the morphology were carried out by using X-ray diffractometry (XRD) and scanning electron microscopy (SEM), respectively. The thermal stability was examined by differential scanning calorimeter (DSC). The DSC trace of powders was performed at a heating rate of $10 \mathrm{~K} / \mathrm{s}$ in an Ar2 atmosphere. The magnetic property was measured by vibrating sample magnetometer (VSM) with maximum applied field of 18000 Oe.

\section{Results and discussion}

\subsection{Phase and morphology of alloy powders}

Fig. 1 shows the XRD of the amorphous powders with different particle size. The typical XRD patterns of amorphous phase can be observed in all the powders with different size. It means that the fabricated powders less than $150 \mu \mathrm{m}$ in diameter are fully amorphous without the crystalline phases. The fast cooling rate can be achieved in the water-atomization process to suppress the formation of crystalline phase in $\mathrm{Fe}_{76} \mathrm{Si}_{13} \mathrm{~B}_{7} \mathrm{Cr}_{2} \mathrm{Mn}_{1} \mathrm{Al}_{1}$ alloy $[10,14]$.

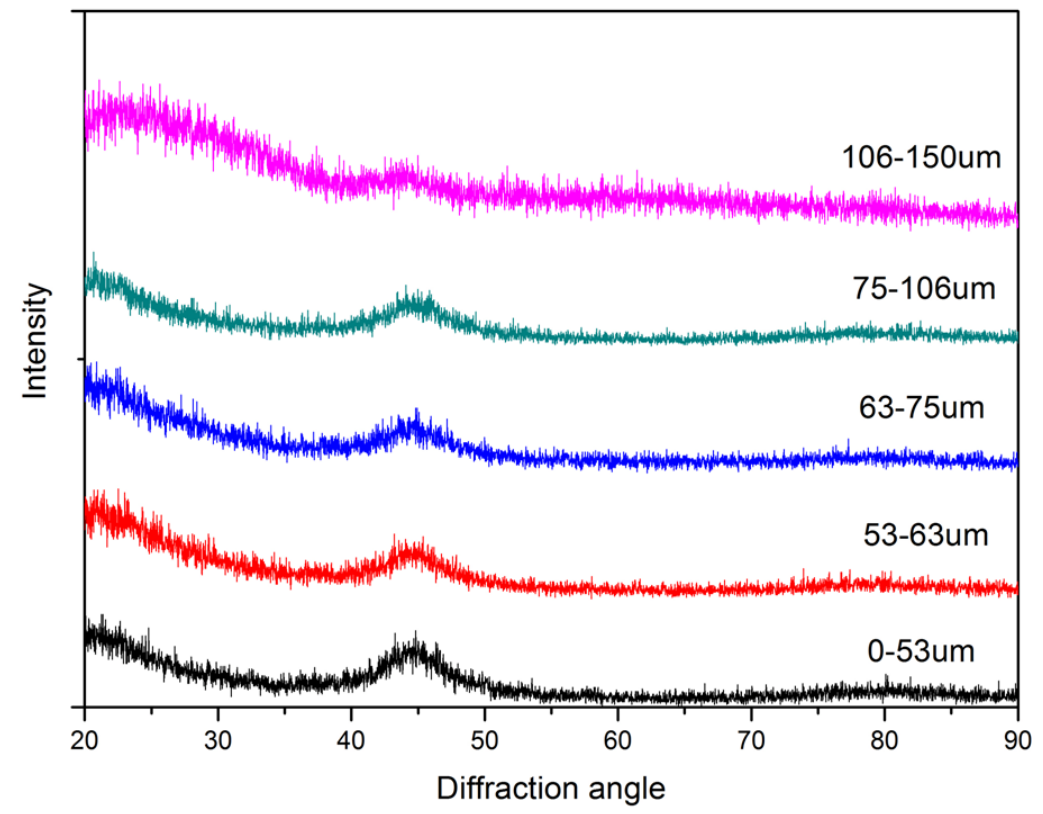

Figure 1. XRD patterns of the as-atomized $\mathrm{Fe}_{76} \mathrm{Si}_{13} \mathrm{~B}_{7} \mathrm{Cr}_{2} \mathrm{Mn}_{1} \mathrm{Al}_{1}$ alloy powders.

Fig. 2 shows the surface morphology and cross section of the as-atomized $\mathrm{Fe}_{76} \mathrm{Si}_{13} \mathrm{~B}_{7} \mathrm{Cr}_{2} \mathrm{Mn}_{1} \mathrm{Al}_{1}$ all oy powders. Fig. $2 \mathrm{a}$ and $2 \mathrm{~b}$ present the surface morphology of the powders. It can be seen that most of the powders are spherical or elliptical apart from several jointed large powders. The difference in sha pe is due to various disintegrating and cooling conditions. Small particles have a fast cooling rate, and complete solidification occurred before they turn to be spherical, while large particles have enough ti me to become spherical under the action of the surface tension [15]. Moreover, the cross section of po wders shows a very smooth structure (fig.2c and 2 d). No tendency of crystalline phases can be found. This is consistent with the results of XRD (fig.1). 


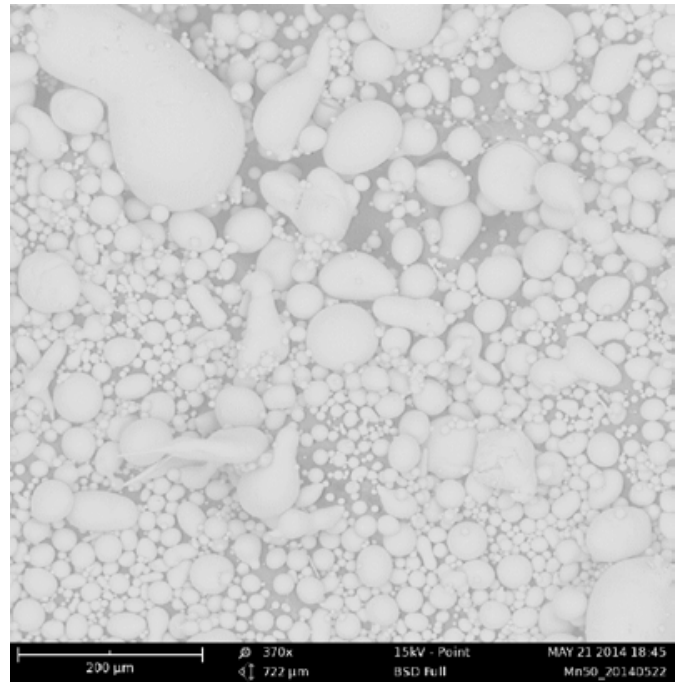

(a)

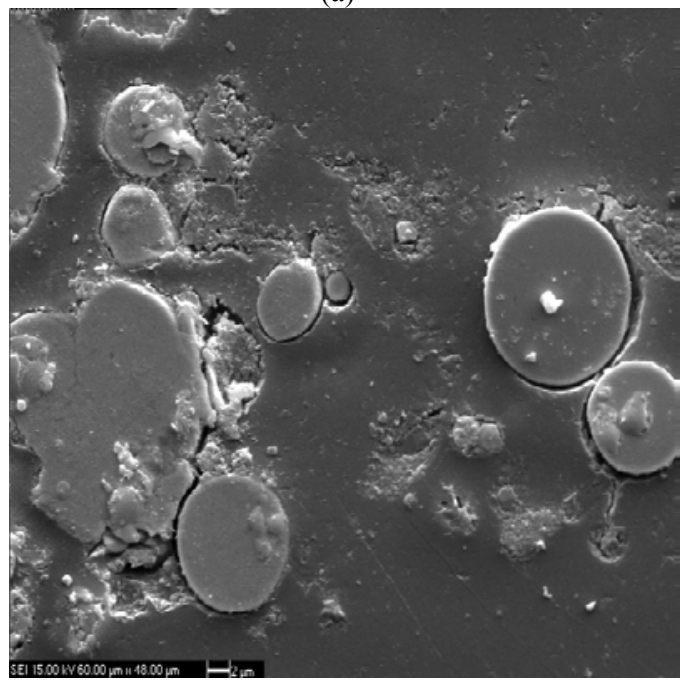

(c)

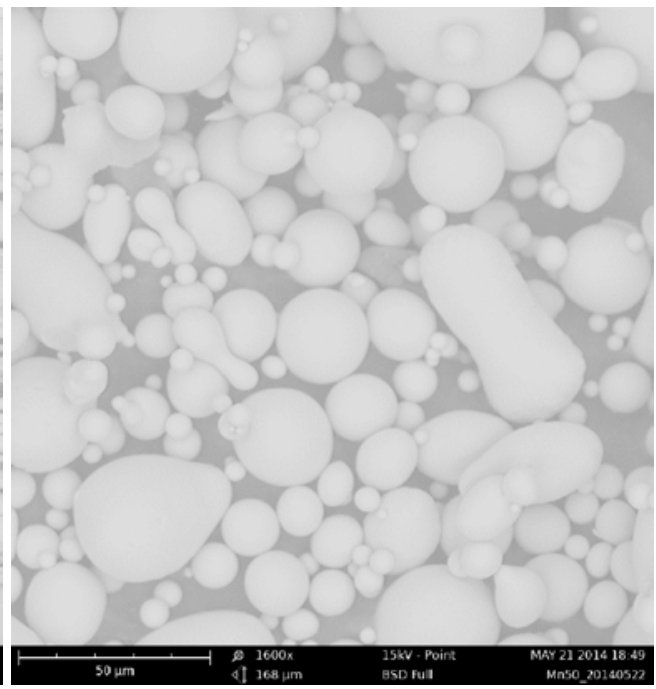

(b)

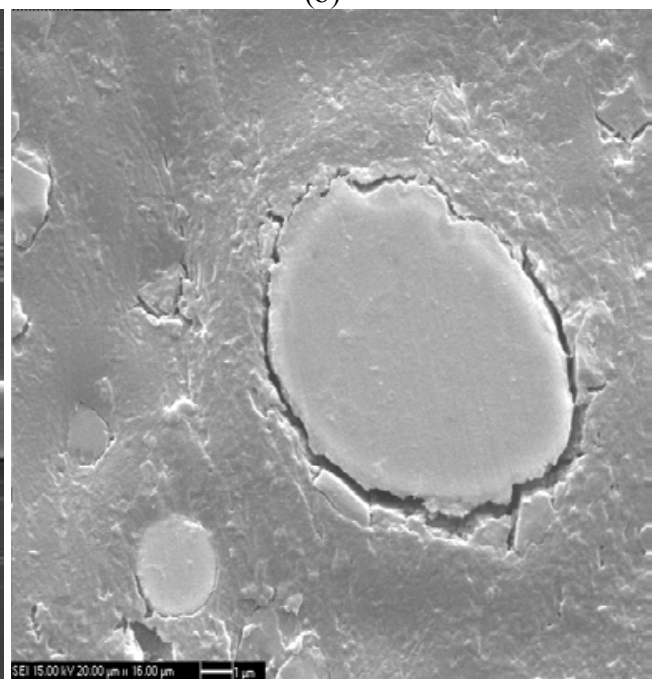

(d)

Figure 2. Surface and cross section of the as-atomized $\mathrm{Fe}_{76} \mathrm{Si}_{13} \mathrm{~B}_{7} \mathrm{Cr}_{2} \mathrm{Mn}_{1} \mathrm{Al}_{1}$ powders. in different zoom scales; surface:(a) small;(b)large; cross section:(c)small;(d) large.

\subsection{Thermal stability and magnetic property}

Fig. 3 shows the DSC trace of the as-atomized $\mathrm{Fe}_{76} \mathrm{Si}_{13} \mathrm{~B}_{7} \mathrm{Cr}_{2} \mathrm{Mn}_{1} \mathrm{Al}_{1}$ alloy powders in the two groups of 0-53 $\mu \mathrm{m}$ and 76-105 $\mu \mathrm{m}$. It can be seen that the measured curves are almost the same for the two grou ps of powders. It indicates that powder size has no effect on the thermal stability. The glass transition $t$ emperature $\mathrm{Tg}$, the crystallization temperature $\mathrm{Tx}$ and $\Delta \mathrm{Tx}(\mathrm{Tx}-\mathrm{Tg})$ of the powders are $743 \mathrm{~K}, 776 \mathrm{~K}$ a nd $33 \mathrm{~K}$ respectively. These powders have good thermal stability. And the glass transition region is ab out $21 \mathrm{~K}$ smaller than that of the as-cast material, reported in Ref [16]. 


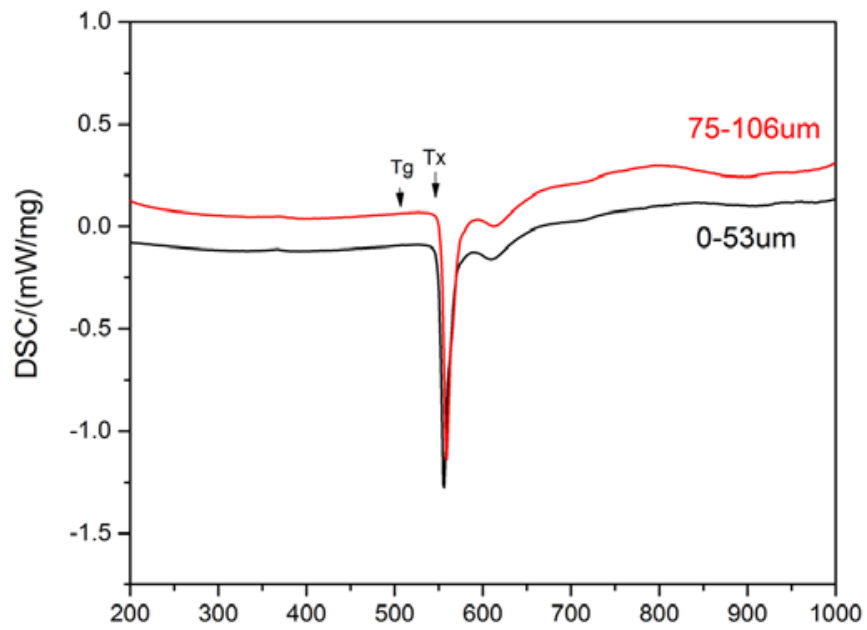

Figure 3. DSC trace of the as-atomized $\mathrm{Fe}_{76} \mathrm{Si}_{13} \mathrm{~B}_{7} \mathrm{Cr}_{2} \mathrm{Mn}_{1} \mathrm{Al}_{1}$ powders.

Fig. 4 shows the hysteresis loops of the five grouped as-atomized Fe76Si13B7Cr2Mn1Al1 glass powders. Table 1 presents the corresponding values of saturation magnetization and coercivity of the as-atomized powder. The five grouped powders possess the similar saturation magnetization and coercivity. The values of saturation magnetization are only varied in a small range of 144.1-159.0 $\mathrm{emu} / \mathrm{g}$ at an average of $151.2 \mathrm{emu} / \mathrm{g}$; the values of coercivity are varied in a small range of 23.6-25.4 Oe at the average of 24.4 Oe.

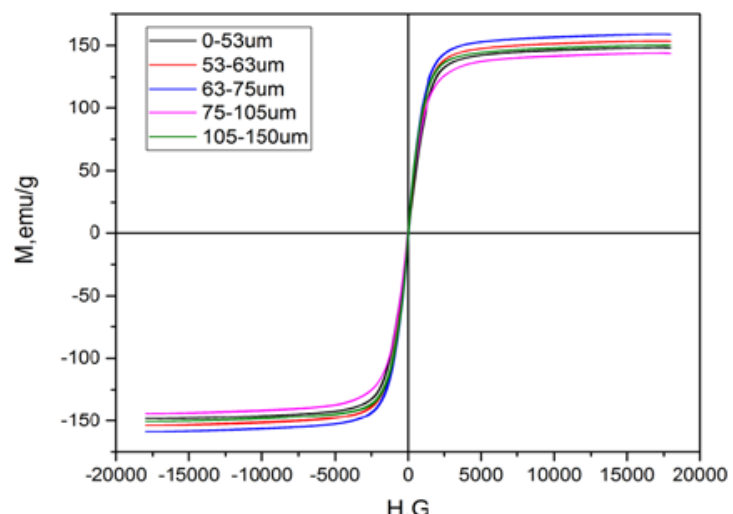

(a)

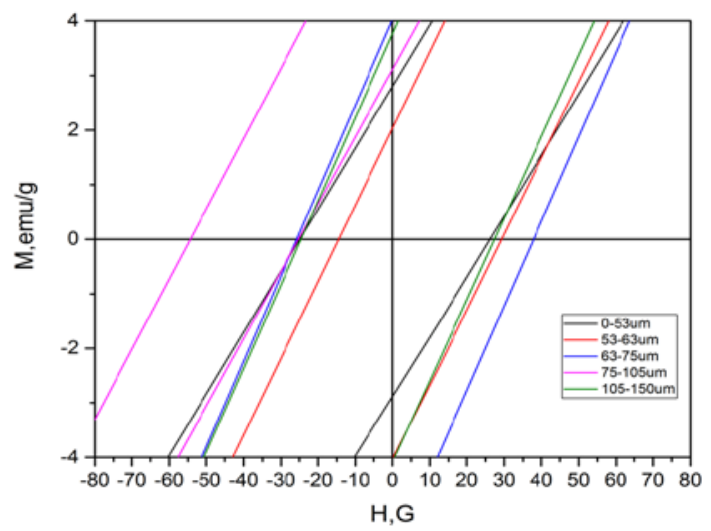

(b)

Figure 4. Hysteresis loops of the five grouped as-atomized $\mathrm{Fe}_{76} \mathrm{Si}_{13} \mathrm{~B}_{7} \mathrm{Cr}_{2} \mathrm{Mn}_{1} \mathrm{Al}_{1}$ glass powders. (a): the hysteresis loops;(b): coercivity.

In order to improve the glass forming ability of $\mathrm{Fe}-\mathrm{Si}-\mathrm{B}$ system amorphous alloy, the $\mathrm{Cr}, \mathrm{Al}, \mathrm{Mn}$ elements were added into the $\mathrm{Fe}-\mathrm{Si}-\mathrm{B}$ system amorphous alloy, which resulting in a remarkable decrease in the saturation magnetization, and the saturation magnetization is lower than the pure $\mathrm{Fe}-$ $\mathrm{Si}-\mathrm{B}$ amorphous alloys. So it is difficult to achieve a good combination of all the desired features in one alloy composition. If we wish to attain the high saturation magnetization, then the alloying elements should maintain low level.

Table 1. The saturation magnetization and coercivity of the as-atomized powders

\begin{tabular}{|c|c|c|c|c|c|c|c|}
\hline $\begin{array}{c}\text { Size } \\
\text { Test }\end{array}$ & $0-53$ & $53-63$ & $63-75$ & $75-105$ & $105-150$ & Average & Error \\
\hline $\mathrm{Ms}(\mathrm{emu} / \mathrm{g})$ & 148.4 & 153.8 & 159.0 & 144.1 & 150.5 & 151.2 & $<0.5$ \\
\hline $\mathrm{Hc}(\mathrm{Oe})$ & 24.8 & 23.6 & 25.4 & 23.7 & 24.6 & 24.4 & $<0.5$ \\
\hline
\end{tabular}




\section{Conclusions}

This paper studied the $\mathrm{Fe}_{76} \mathrm{Si}_{13} \mathrm{~B}_{7} \mathrm{Cr}_{2} \mathrm{Mn}_{1} \mathrm{Al}_{1}$ alloy powders that prepared by water atomization. Phase analysis shows that the completely amorphous phase is generated in the powders less than $150 \mu \mathrm{m}$ in diameter. It means that metallic glass powders can be successfully manufactured by water atomization. And it is also can be concluded that the atomized powders have good thermal stability and soft magnetic properties. The glass transition temperature $\mathrm{Tg}$ of $743 \mathrm{~K}$ and the crystallization temperature Tx of $776 \mathrm{~K}$ are obtained in powders regardless of the variation of powder size. The maximum value of saturation magnetization is as high as $159.0 \mathrm{emu} / \mathrm{g}$ and the average value of different particle sizes is $151.2 \mathrm{emu} / \mathrm{g}$.

\section{Acknowledgements}

This work was financially supported by China National Basic Research Development Project (973 Program: No.2010CB630802), and China National Natural Science Foundation (No.51074104). XRD, SEM and TEM were made in the Instrumental Analysis \& Research Center of SHU. We expressed our sincere thanks for their support.

\section{References}

1. A. Inoue and J.S. Gook. Fe-based ferromagnetic glassy alloys with wide super cooled liquid region. Mater. Trans., JIM 36: 1180-1183 (1995).

2. A. Inoue, B.L. Shen, New Fe-based bulk glassy alloys with high saturated magnetic flux density of 1.4 to 1.5 Tesla, Mater. Sci. Eng. A375-377, 302-306(2004).

3. M. Hagiwara, A. Inoue, T. Masumoto, Mechanical properties of $\mathrm{Fe}-\mathrm{Si}-\mathrm{b}$ amorphous wires produced by in-rotating-water spinning method, Met. Trans. 13A, 373-382 (1982).

4. A. Inoue, Y. Shinohara, J.S. Gook, Thermal and magnetic properties of bulk Fe-based glassy alloys prepared by copper mold casting, Mater. Trans. JIM 36, 1427-1433 (1995).

5. T. Zhang, A. Inoue, Bulk glassy alloys in (Fe, Co, Ni)-Si-B system, Mater. Tran. 42, 1015-1018 (2001).

6. J. Shen, Q.J. Chen, J.F. Sun, Exceptionally high glass-forming ability of an FeCoCrMoCBY alloy, Appl. Phys. Lett. 86, 1-3 (2005).

7. H. X. Li, K. B. Kim and S. Yi: 'Enhanced glass-forming ability of Fe-based bulk metallic glasses prepared using hot metal and commercial raw materials through the optimization of Mo content', Scr. Mater., 56, 1035-1038, (2007).

8. X. J. Gu, S. J. Poon, G. J. Shiflet and M. Widom: 'Ductility improvement of amorphous steels: roles of shear modulus and electronic structure', Acta Mater., 56, 88-94 (2008).

9. M. Mitera, T. Masumoto, N.S. Kazama, Effect of silicon addition on the magnetic

10. properties of Fe-B-C amorphous alloys, J. Appl. Phys. 50, 7609-7611(1979).

11. Yong Liu, Sen Niu, Fei Li, Yitian Zhu, Yuehui He, Preparation of amorphous Fe-based magnetic powder by water atomization. Powder Technology 213, 36-40 (2011)

12. H.X. Li, S.L. Wang, S. Yi, Z.B. Jiao, Y. Wu, Z.P. Lu, Glass formation and magnetic properties of $\mathrm{Fe}-\mathrm{C}-\mathrm{Si}-\mathrm{B}-\mathrm{P}-(\mathrm{Cr}-\mathrm{Al}-\mathrm{Co})$ bulk metallic glasses fabricated using industrial raw materials, J. Magn. Magn. Mater. 321, 2833-2837 (2009).

13. M. Yagi, I. Endo, I. Otsuka, H. Yamamoto, R. Okuno, H. Koshimoto, A. Shintani,

14. Magnetic properties of $\mathrm{Fe}$-based amorphous powder cores produced by a hot pressing

15. method, J. Magn. Magn. Mater. 215-216, 284-287 (2000).

16. I. Endo, I. Otsuka, R. Okuno, A. Shintani, M. Yoshino, M. Yagi, Fe-based amorphous softmagnetic powder produced by spinning water atomization process (SWAP),IEEE Trans. Mag. 35, 3385-3387 (1999).

17. S. He, Y. Liu, S. Guo, Cooling rate calculation of non-equilibrium aluminum alloy powders prepared by gas atomization, Rare Metal Mater. Eng. 38, 353-356 (2009). 
18. X.Z. Che, Stress relief and magnetism optimization in amorphous Fe79B16Si5 alloy, Acta Metal. Sin. 31, B418-B422 (1995).

19. A. Makino, C. Chang, T. Kubota, A. Inoue, Soft magnetic Fe-Si-B-P-C bulk metallic glasses without any glass-forming metal elements, J. Alloys Comp. 483, 616-619 (2009). 